\title{
Advanced Surface Ablation in Mild (Fruste) Keratoconus: A Case Report
}

Louise P. G. Esporcatte · Marcella Q. Salomão · Nelson B. Sena Jr. ·

Bernardo T. Lopes $\cdot$ Renato Ambrósio Jr.

Received: March 8, 2020 / Published online: April 22, 2020

(C) The Author(s) 2020, corrected publication 2021

\section{ABSTRACT}

Corneal ectasia is a complication of refractive surgery, and keratoconus is a contraindication to this type of procedure. Surface ablation may be an option for selected cases of mild

Digital Features To view digital features for this article go to https://doi.org/10.6084/m9.figshare.12130296.

L. P. G. Esporcatte · M. Q. Salomão ·

B. T. Lopes · R. Ambrósio Jr. (₫)

Rio de Janeiro Corneal Tomography and

Biomechanics Study Group, Rio de Janeiro, Brazil

e-mail: dr.renatoambrosio@gmail.com

L. P. G. Esporcatte · M. Q. Salomão - R. Ambrósio Jr. Instituto de Olhos Renato Ambrósio, Rio de Janeiro, Brazil

L. P. G. Esporcatte - M. Q. Salomão - R. Ambrósio Jr. Department of Ophthalmology, Federal University of São Paulo, São Paulo, Brazil

M. Q. Salomão · R. Ambrósio Jr.

Brazilian Study Group of Artificial Intelligence and Corneal Analysis (BrAIN), Rio de Janeiro, Brazil

M. Q. Salomão

Instituto Benjamin Constant, Rio de Janeiro, Brazil

B. T. Lopes

School of Engineering, University of Liverpool, Liverpool, UK

N. B. Sena Jr. · R. Ambrósio Jr.

Department of Ophthalmology, Federal University the State of Rio de Janeiro (UNIRIO), Rio de Janeiro, Brazil keratoconus, with patient education being fundamental to this treatment as well as a complete evaluation of the cornea and optical properties of the patient. Here we report the clinical outcome of a patient 15 years after advanced surface ablation in a case of mild (fruste) keratoconus.

Keywords: Corneal ectasia; Keratoconus; Photorefractive keratectomy 


\section{Key Summary Points}

Keratoconus is a noninflammatory, bilateral, progressive, asymmetric, and degenerative disease of the cornea characterized by stromal thinning and increased corneal curvature, with a prevalence of about $1 / 20,000$ general population, depending on the population described.

Corneal ectasia is a complication of refractive surgery, and keratoconus has long been a contraindication to this type of procedure due to the risk of postoperative progression of the disease process, especially with laser in situ keratomileusis.

The case described here shows that surface ablation may be a treatment option for selected cases of mild keratoconus, with patient education being fundamental to treatment as well as a complete evaluation of the cornea and optical properties of the patient.

Surface ablation can be an excellent surgical option primarily in patients with contact lens intolerance who understand and accept the risk for progression and need for further therapeutic procedures.

\section{INTRODUCTION}

Keratoconus (KC) is a noninflammatory, bilateral, progressive, asymmetric, and degenerative disease of the cornea characterized by stromal thinning and increased corneal curvature, with a prevalence of about $1 / 20,000$ general population, depending on the population described $[1,2]$. Although refractive correction with spectacles or contact lenses can provide acceptable improvement in visual acuity for many of these patients, the quality of vision might still be reduced in some cases due to irregular astigmatism associated with the disease [3].

Corneal refractive surgery, especially laser in situ keratomileusis (LASIK), in patients with such irregular corneas has long been contraindicated due to the risk of postoperative progression of the disease process. The flap created increases alterations to the biomechanical properties and weakens even more the corneal tissue, which in turn renders the cornea more prone to keratectasia [4]. However, numerous studies report the safety of surface ablation procedures in milder forms of $\mathrm{KC}$, with photorefractive keratectomy (PRK) alone or even PRK followed by corneal collagen crosslinking $[1,5,6]$. Current regimes for PRK in such cases utilize topography-guided ablation profiles intended to reduce corneal surface irregularities and therefore improve vision quality. Although corneal ectasia has been previously described after PRK in suspected keratoconus cases [7], other studies report encouraging results $[6,8]$.

A primary concern associated with refractive surgery in patients with atypical corneal topography is that the procedure might increase the speed of progression of the ectatic process [9]. Retrospective case-control studies of patients with ectasia suggest five main risk factors for progression of the disorder after laser vision correction: (1) abnormal preoperative topography; (2) low residual bed thickness; (3) young age; (4) low preoperative corneal thickness; and (5) high myopia [10].

In this article, we describe the clinical outcome of a patient diagnosed with mild $\mathrm{KC}$ who underwent advanced surface ablation in both eyes and whose condition has been stable for 15 years.

Presentation of this case has been approved by the Ethics committee of Universidade Federal de São Paulo (UNIFESP/SP 2018; no. 2.568.770). The patient reported in the case report signed an informed consent form.

\section{CASE REPORT}

A 33-year-old male patient presented in 2004 seeking refractive surgery. Distance-corrected 


\section{OCULUS - PENTACAM 4 Maps Refractive}

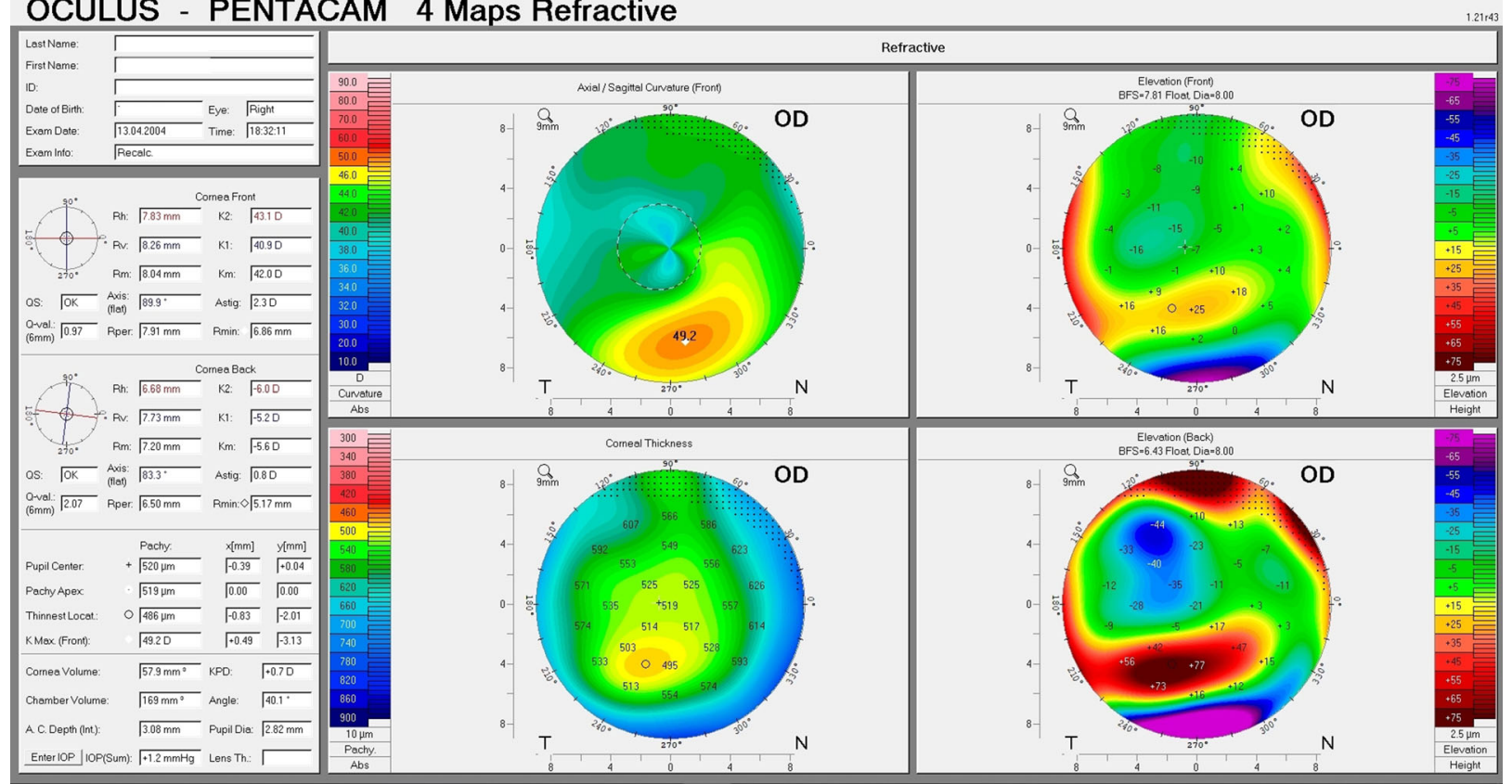

Fig. 1 Pentacam refractive 4-maps of the patient's right eye $(O D)$ in 2004 , showing the thinnest pachymetry to be $486 \mu \mathrm{m}$; the simulated keratometry (Sim K keratometry) to be $40.9 \times 89.9 \times 43.1$, and maximum keratometry (Kmax) to be 49.2

\section{OCULUS - PENTACAM 4 Maps Refractive}

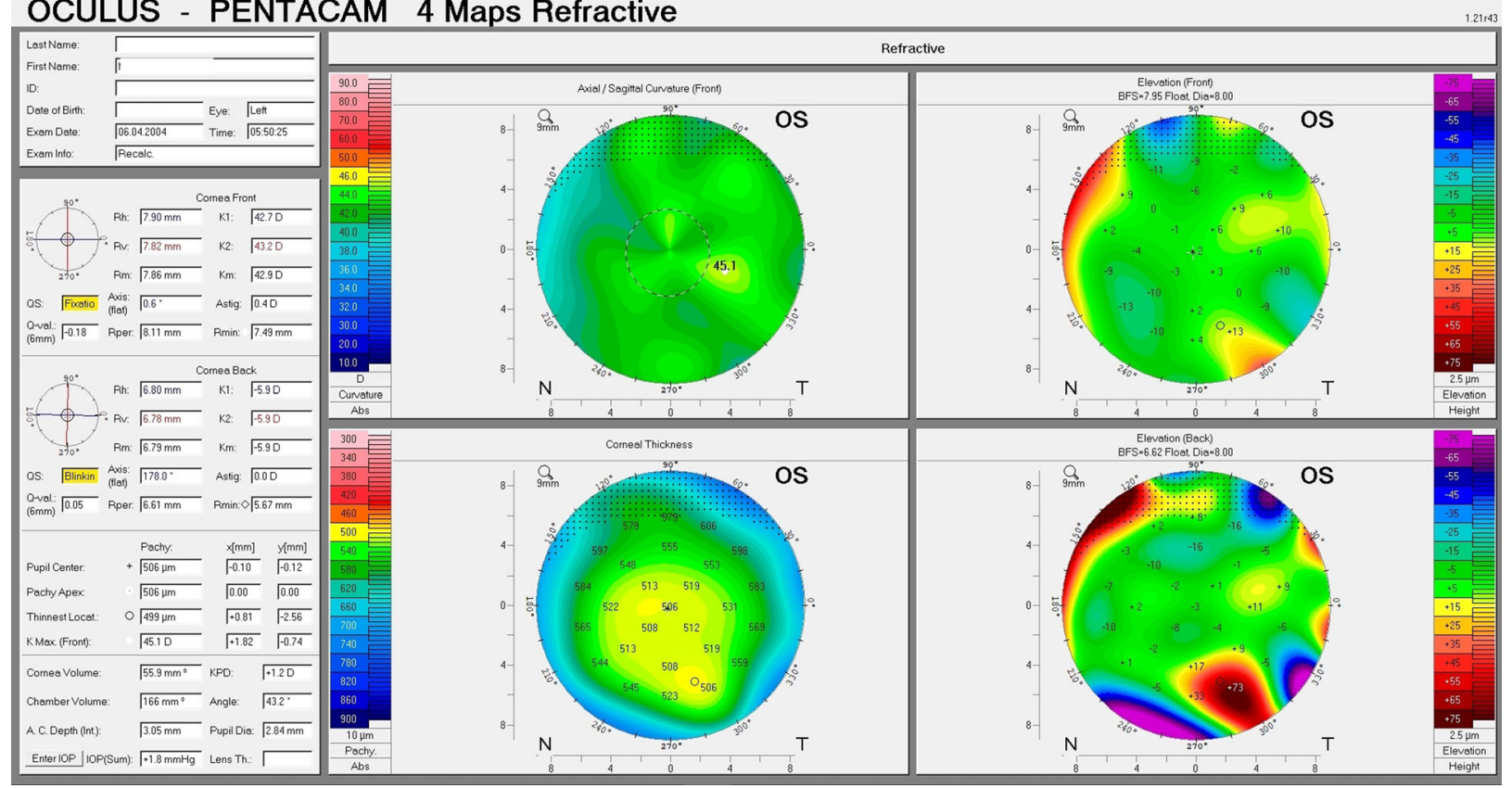

Fig. 2 Pentacam refractive 4-maps of the patient's left eye $(O S)$ in 2004, showing the thinnest pachymetry to be $499 \mu \mathrm{m}$; the Sim K keratometry to be $42.7 \times 6 \times 43.2$ OS, and Kmax to be 45.1

visual acuity (DCVA) was 20/30 (-4.00/- 2.50 $\times 86)$ in the right eye (OD) and 20/20 (- 7.50/$0.50 \times 80)$ in the left eye $(\mathrm{OS})$. The results of the silt lamp exam and fundoscopy were unremarkable. 


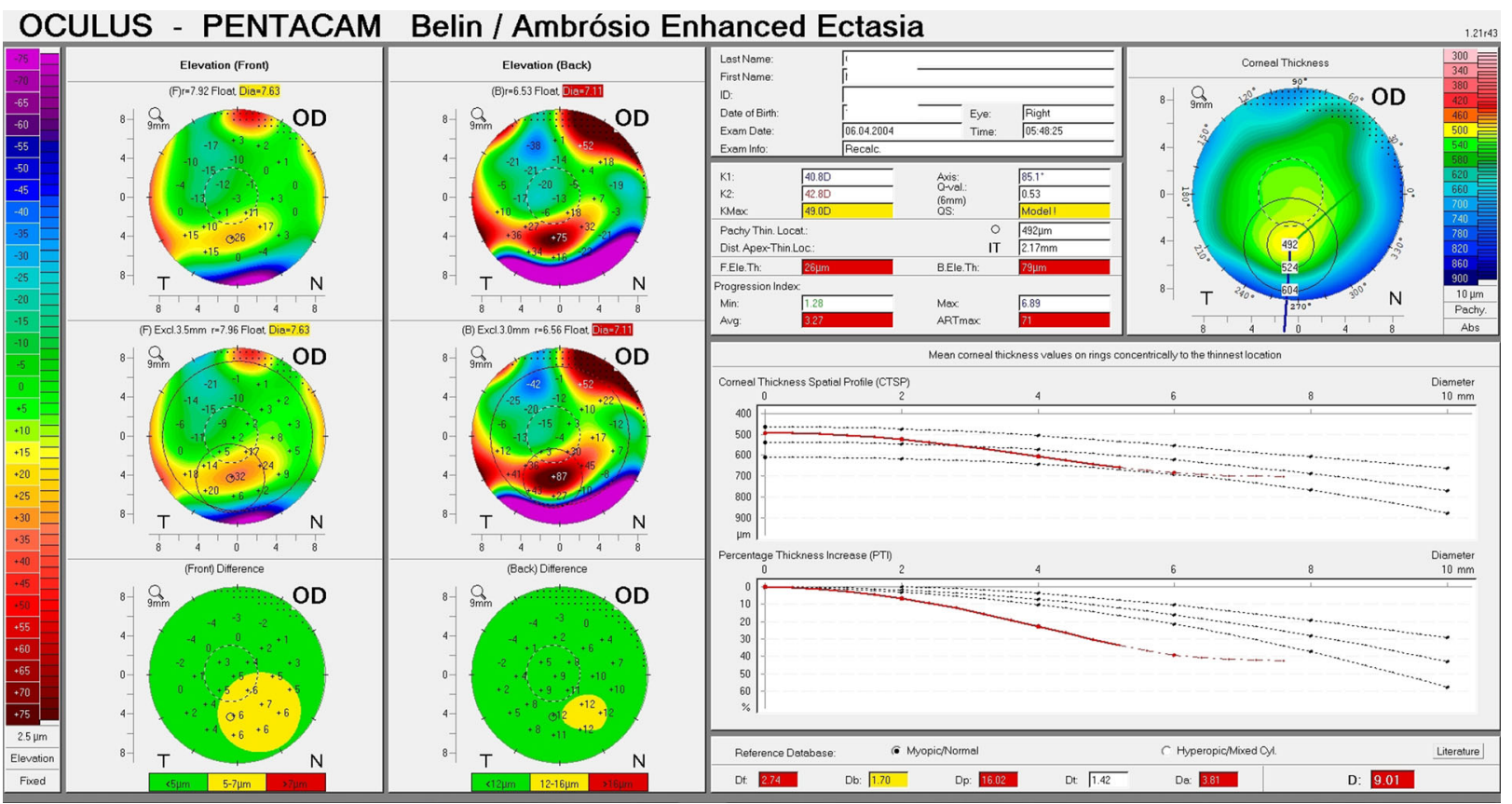

Fig. 3 Pentacam Belin/Ambrósio enhanced ectasia (BAD-D) index of the patient's right eye $(O D)$ before the customized photorefractive keratectomy (PRK). BAD-D index $=9.01$ (index calculated from the data from 2004)

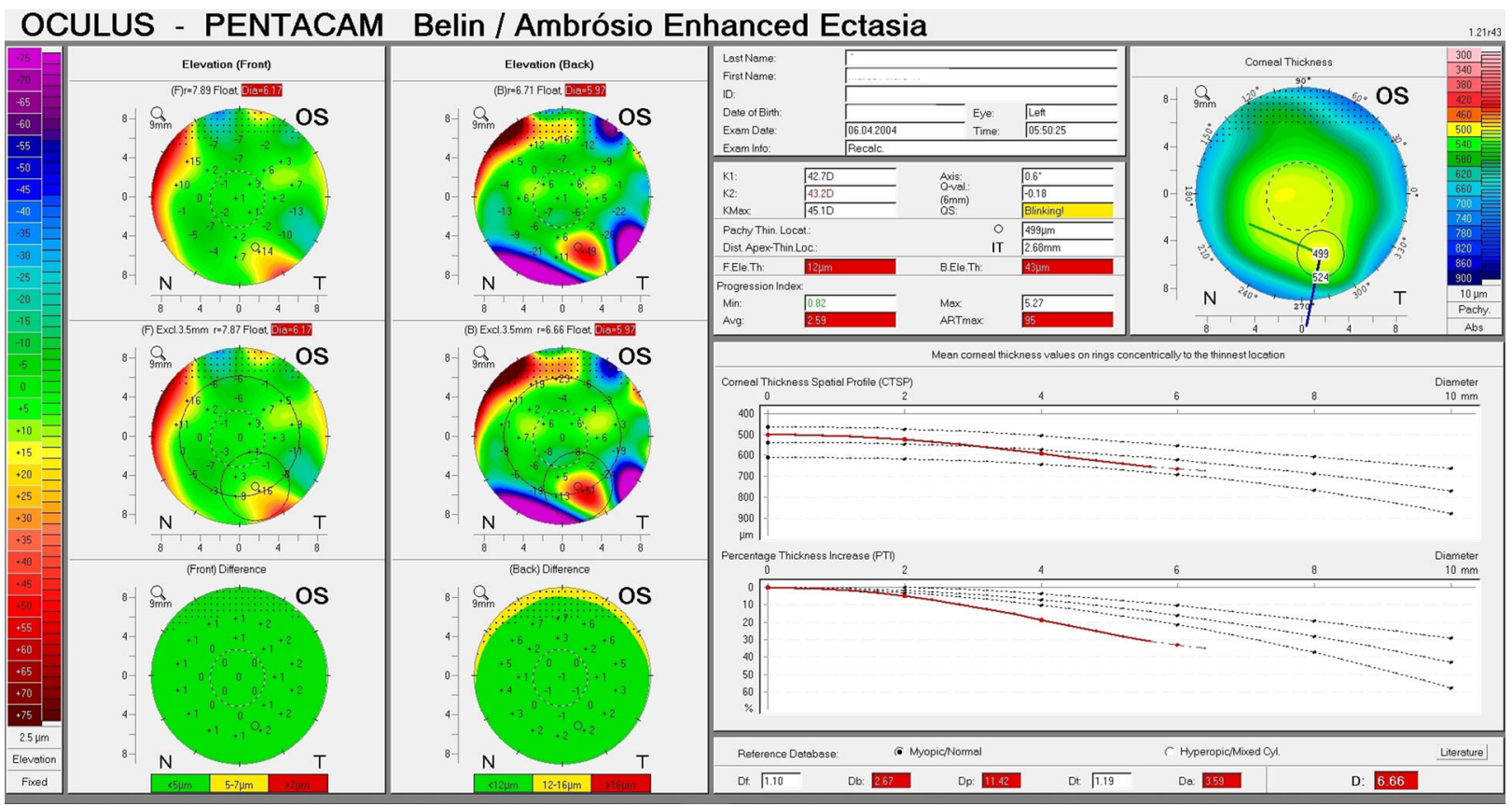

Fig. 4 Pentacam BAD-D index of the patient's left eye (OS; fellow eye to that shown in Fig. 3). BAD-D index $=6.66$

A mild keratoconus pattern was observed in the topometric and tomographic exams: (1) thinnest pachymetry measurements were
$486 \mu \mathrm{m}$ OD and $499 \mu \mathrm{m}$ OS; (2) simulated keratometry (Sim K keratometry) results were 40.9 @89.9 $\times 43.1$ OD and 42.7@ $6^{\circ} \times 43.2$ OS; (3) 


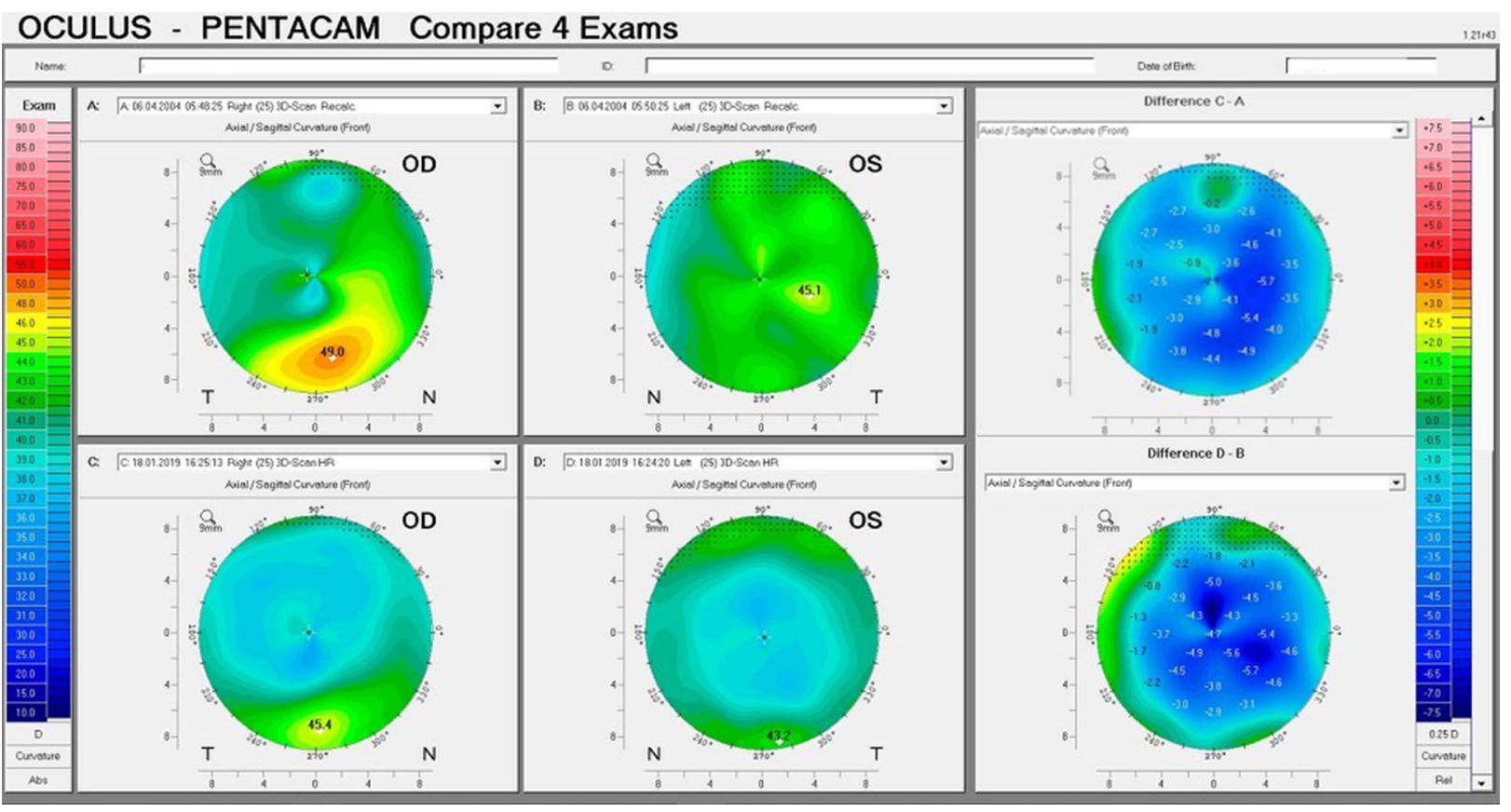

Fig. 5 Biomechanical/Tomographic Assessment (Ambrósio, Roberts \& Vinciguerra [ARV]) post-laser vision correction assessment of the right $(O D)$ and left $(O S)$ eyes. a, c Anterior curvature maps of OD in 2004 and

maximum keratometry (Kmax) results were 49.2 OD and 45.1 OS (Figs. 1, 2). At the time of the surgery there was no Belin/Ambrósio enhanced ectasia index (BAD-D) for the OCULUS Pentacam ${ }^{\circledR}$ (OCULUS Optikgeräte $\mathrm{GmbH}$, Wetzlar Germany); therefore, we used data from 2004 to calculate it (9.01 OD and 6.66 OS (Figs. 3, 4).

The patient was intolerant to glasses and contact lenses and, after discussing the risks and benefits of surgery, he underwent customized PRK in both eyes. The patient was advised to avoid rubbing his eyes and to return to his current follow-up schedule of every month in the first year and every 4 months thereafter. Fifteen years after surgery, a stable flattening could still be observed in both eyes, with no changes in anterior corneal elevation (Fig. 5). The DCVA was $20 / 20(0 /-1.00 \times 41)$ and $20 / 30$ $(-1.50 /-1.25 \times 8)$ in OD and OS, respectively. The Biomechanical/Tomographic Assessment (Ambrósio, Roberts \& Vinciguerra [ARV]) postlaser vision correction from the right and left eyes is shown Figs. 6 and 7, respectively.
2019, respectively. b, d Anterior curvature maps of OS in 2004 and 2019, respectively. Right panel: Note there is no evidence of progression of the ectatic disease in both eyes (c-a; d-b)

\section{DISCUSSION}

In the case described here, we followed Tamayo et al.'s criteria for indicating customized PRK in mild (fruste) KC: age > 26 years; maximum keratometry $<56.00$ diopters (D); central corneal thickness (CCT) $>430 \mu \mathrm{m}$; manifest astigmatism $<5.0 \mathrm{D}$; uncorrected visual acuity better than 20/400; no scars or haze in the visual axis; residual stromal bed $>350 \mu \mathrm{m}$; and absence of a very inferiorly decentered cone [11]. Based on these criteria, these authors suggest that PRK is an excellent surgical option for cases of low and moderate $\mathrm{KC}$ and for patients with contact lens intolerance, handicapped VA with glasses, and with no contraindication for surgery, advocating that it can be considered to be a temporary relief for a future corneal transplant [11].

It is important to highlight that a phakic intraocular lens is always an option for borderline cases with moderate susceptibility for ectasia progression and/or mild $\mathrm{KC}$, but in this 


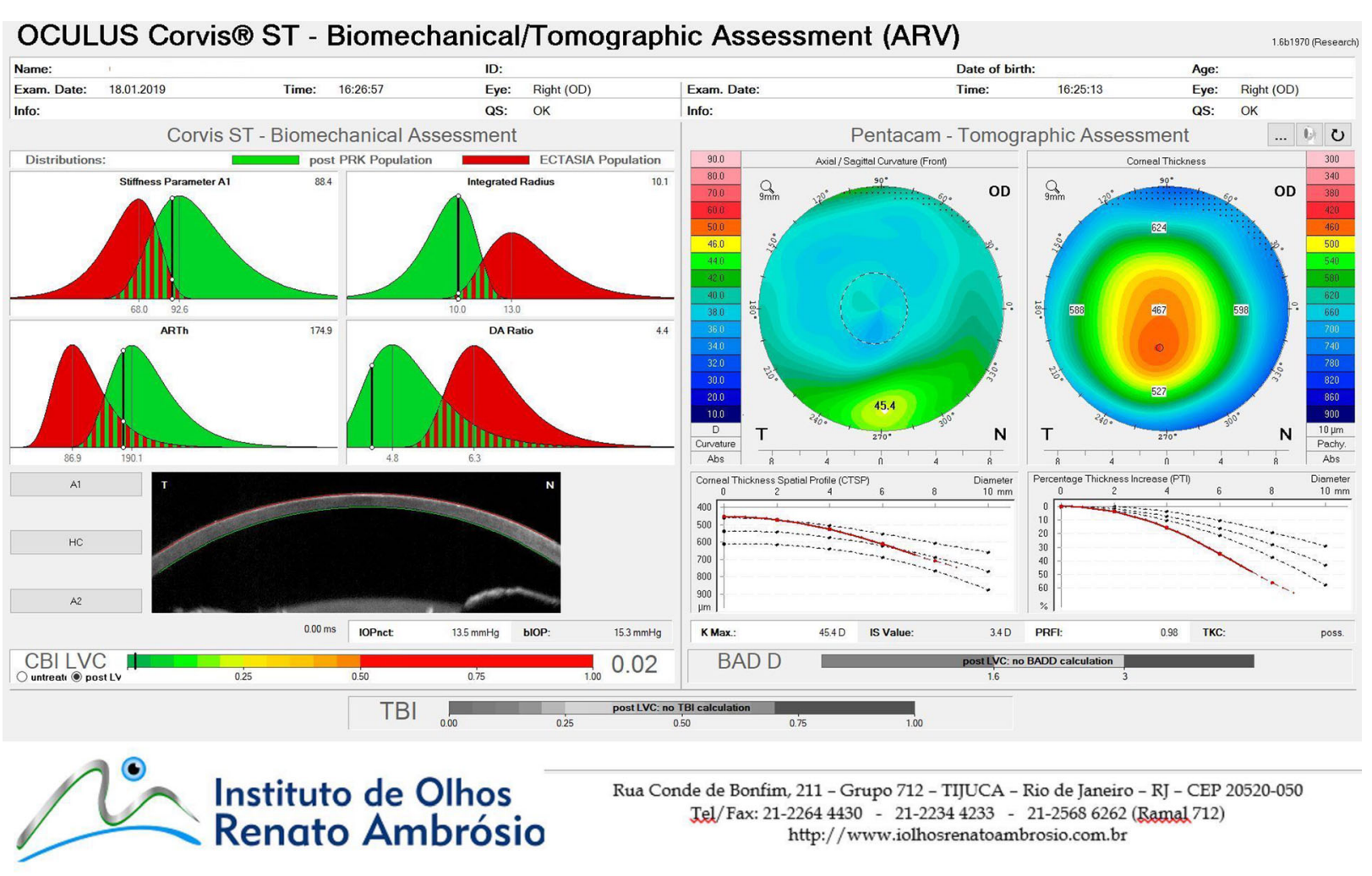

Fig. 6 The ARV (Ambrósio, Roberts \& Vinciguerra) Biomechanical and Tomographic Assessment display from the right eye $(O D)$ showing the Corvis Biomechanical Index post-laser vision correction (CBI LVC) of this case

case, the level of correction was considered to be preferable for surface ablation.

In a prospective noncomparative case series, in which 11 eyes of eight contact lens-intolerant patients with forme fruste $\mathrm{KC}$ were treated, the authors concluded that topography-guided surface ablation is a promising option to rehabilitate vision in contact lens-intolerant patients, based on achieving a statistically significant reduction of manifest refractive error, corneal irregularity, and ghosting [12]. In a prospective study, Chelala and coworkers also evaluated the visual outcome of PRK in 119 eyes from 72 patients with mild to moderate stable KC and concluded that PRK was a safe and effective procedure for improving uncorrected vision in patients with mild refractive errors. However, these authors do warn that a close follow-up of patients is needed to detect any progression of the disease [1].

The concerns surrounding the indication of PRK in patients who may have atypical topography have also been addressed because these patients may have an increased risk for corneal instability associated with laser vision correction (LVC). Corneal instability is generally thought to be less of a risk with PRK than with LASIK. In cases of topographic irregularities, surface LVC has been demonstrated to be successful in improving uncorrected distance visual acuity with a moderately low rate of complications [13]. Ming Chen reviewed articles published between 1980 and 2012 in a search for evidence to determine whether PRK or LASIK is the better option for laser vision correction for patients with atypical corneal topography [10]. This author concluded that even though PRK may be the safer procedure when compared to LASIK for those patients, there is a possible risk of worsening corneal ectasia. The authors of a retrospective follow-up study (1998-2013) of 28 eyes of 23 patients (age 17-60 years) with grade 1-3 keratoconus that received topography-guided PRK also concluded 


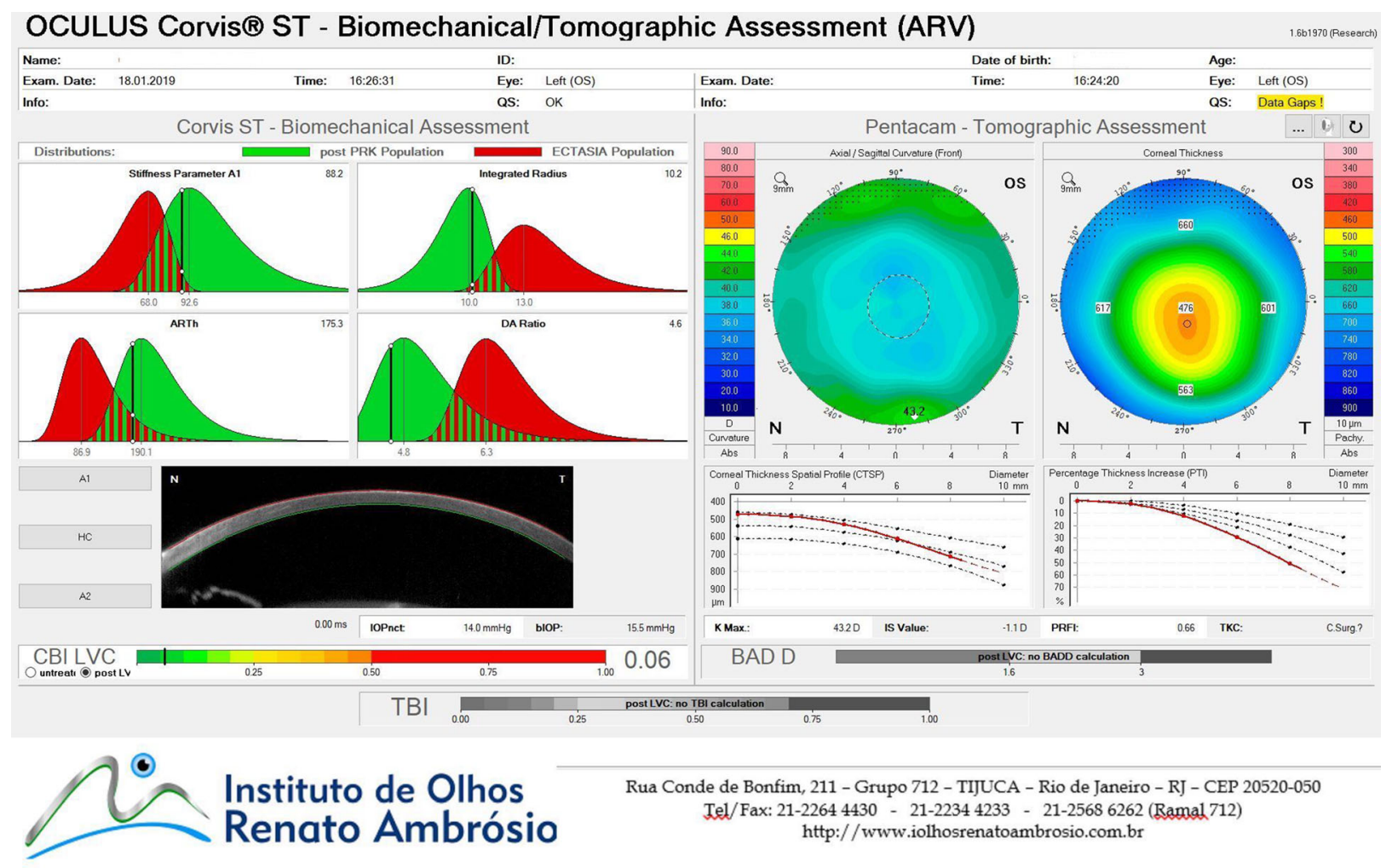

Fig. 7 The ARV Biomechanical and Tomographic Assessment display from the left eye (OS; fellow eye to that shown in Fig. 5)

that topography-guided PRK in keratoconus might be effective for reducing myopia and astigmatism [14]. An additional prospective study evaluated the long-term outcomes of PRK in patients with mild to moderate $\mathrm{KC}$ in patients older than 40 years without progression in the last 2 years, with residual CCT $\geq 400 \mu \mathrm{m}$ [15]. These authors concluded that PRK did not induce KC progression in such patients and suggested that a residual CCT $\geq 450 \mu \mathrm{m}$ would appear to be sufficient to prevent the ectasia. In contrast, Randleman et al. reported two patients who developed bilateral corneal ectasia after PRK, in which one patient manifested early KC preoperatively and the second patient had a family history suspicious for KC, with a sibling who had bilateral corneal transplantation at a young age [16].

\section{CONCLUSION}

Surface ablation may be an option for selected cases of mild keratoconus. Patient education is fundamental, as is a complete evaluation of the cornea and optical properties of the patient. We advocate considering Tamayo et al.'s criteria for enhancing safety [11] when planning custom ablations of such procedures, which can be an excellent surgical option mostly in patients with contact lens intolerance who understand and accept the risk for progression and require further therapeutic procedures.

\section{ACKNOWLEDGMENTS}

We thank the patient for allowing his case to be presented in this article. 
Funding. No funding or sponsorship was received for this study or publication of this article.

Authorship. All named authors meet the International Committee of Medical Journal Editors (ICMJE) criteria for authorship for this article, take responsibility for the integrity of the work as a whole, and have given their approval for this version to be published.

Disclosures. Bernardo T. Lopes and Renato Ambrósio Jr are consultants for OCULUS Optikgeräte $\mathrm{GmbH}$ (Wetzlar, Germany). Louise P.G. Esporcatte, Marcella Q. Salomão, and Nelson B. Sena Jr declare that they have no competing interests. Renato Ambrósio $\mathrm{Jr}$ is a member of the journal's Editorial Board. The authors have no relevant financial disclosures regarding the subject matter or materials discussed in the article.

Compliance with Ethics Guidelines. Presentation of this case has been approved by the Ethics committee of Universidade Federal de São Paulo (UNIFESP/SP 2018; no. 2.568.770). The patient reported in the case report signed an informed consent form.

Data Availability. This article is a case report. Data sharing is not applicable to this article as no datasets were generated or analyzed during the current study.

Open Access. This article is licensed under a Creative Commons Attribution-NonCommercial 4.0 International License, which permits any non-commercial use, sharing, adaptation, distribution and reproduction in any medium or format, as long as you give appropriate credit to the original author(s) and the source, provide a link to the Creative Commons licence, and indicate if changes were made. The images or other third party material in this article are included in the article's Creative Commons licence, unless indicated otherwise in a credit line to the material. If material is not included in the article's Creative Commons licence and your intended use is not permitted by statutory regulation or exceeds the permitted use, you will need to obtain permission directly from the copyright holder. To view a copy of this licence, visit http:// creativecommons.org/licenses/by-nc/4.0/.

\section{REFERENCES}

1. Chelala E, Rami HE, Dirani A, Fadlallah A, Fakhoury $\mathrm{O}$, Warrak E. Photorefractive keratectomy in patients with mild to moderate stable keratoconus: a five-year prospective follow-up study. Clin Ophthalmol. 2013;7:1923-8.

2. Rabinowitz YS. Keratoconus. Surv Ophthalmol. 1998;42:297-319.

3. Jhanji V, Sharma N, Vajpayee RB. Management of keratoconus: current scenario. Br J Ophthalmol. 2011;95:1044-50.

4. Bühren J, Schäffeler T, Kohnen T. Preoperative topographic characteristics of eyes that developed postoperative LASIK keratectasia. J Refract Surg. 2013;29:540-9.

5. Kymionis GD, Portaliou DM, Kounis GA, Limnopoulou AN, Kontadakis GA, Grentzelos MA. Simultaneous topography-guided photorefractive keratectomy followed by corneal collagen crosslinking for keratoconus. Am J Ophthalmol. 2011;152:748-55.

6. Guedj M, Saad A, Audureau E, Gatinel D. Photorefractive keratectomy in patients with suspected keratoconus: five-year follow-up. J Cataract Refract Surg. 2013;39:66-73.

7. Dawson DG, Randleman JB, Grossniklaus HE, et al. Corneal ectasia after excimer laser keratorefractive surgery: histopathology, ultrastructure, and pathophysiology. Ophthalmology. 2008;115:2181-91.

8. Cennamo G, Intravaja A, Boccuzzi D, Marotta G, Cennamo G. Treatment of keratoconus by topography-guided customized photorefractive keratectomy: two-year follow-up study. J Refract Surg. 2008;24:145-9.

9. Randleman JB, Woodward M, Lynn MJ, Stulting RD. Risk assessment for ectasia after corneal refractive surgery. Ophthalmology. 2008;115:37-50.

10. Chen M. Laser vision correction for patients with atypical topography of cornea, LASIK vs A review. PRK: A review; 2012. 
11. Tamayo GE, Serrano MG. Treatment of irregular astigmatism and keratoconus with the VISX C-CAP method. Int Ophthalmol Clin. 2003;43:103-10.

12. Koller T, Iseli HP, Donitzky C, Ing D, Papadopoulos $\mathrm{N}$, Seiler T. Topography-guided surface ablation for forme fruste keratoconus. Ophthalmology. 2006;113:2198-202.

13. Hardten DR, Gosavi VV. Photorefractive keratectomy in eyes with atypical topography. J Cataract Refract Surg. 2009;35:1437-44.
14. Tambe DS, Ivarsen A, Hjortdal J. Photorefractive Keratectomy in Keratoconus. Case Rep Ophthalmol. 2015;6:260-8.

15. Khakshoor H, Razavi F, Eslampour A, Omdtabrizi A. Photorefractive keratectomy in mild to moderate keratoconus: outcomes in over 40-year-old patients. Indian J Ophthalmol. 2015;63:157-61.

16. Randleman JB, Caster AI, Banning CS, Stulting RD. Corneal ectasia after photorefractive keratectomy. J Cataract Refract Surg. 2006;32:1395-8. 